\title{
Structure and Morphology of Uniform-Sized Nanoscale Bimetallic Catalyst
}

\author{
D. Liu, ${ }^{*}$ H. Xie*, H. J. Ploehn*, C. T. Williams*, and J. Y. Howe** \\ *Department of Chemical Engineering, University of South Carolina, Columbia, SC 29208 \\ **Metals and Ceramics Division, Oak Ridge National Laboratory, Oak Ridge, TN 38831
}

Bimetallic catalysts have found very important applications in large-scale industrial processes such as naphtha reforming, automobile exhaust clean-up, and direct methanol fuel cells. [1] The catalytic behavior of such materials is dramatically affected by the nanostructure of the bimetallic particles, which varies significantly with the preparation method. Conventional methods utilizing inorganic salt precursor, such as incipient wetness impregnation or coprecipitation, attempt to control the morphology and composition of metal particles by optimizing precursor solutions and the pretreatment procedures have met limited success. A new approach is to use dendrimers as templates/stabilizer for synthesis of encapsulated nanoparticles immobilized on a suitable high surface area support. Dendrimers [2] are mono-dispersed, hyperbranched polymers that emanate from a central core with repetitive branching unit. While possessing a very dense exterior, they contain hollow pockets as ideal nanoscale containers. They can exert control over size and compositions of nanoparticles, hence tune the catalytic properties. Here, we report TEM and FTIR studies on dendrimer-derived bimetallic Pt-Cu catalyst.

Dendrimer-derived Pt-Cu nanoparticles were prepared by mixing a 1:40 molar ratio of G4-OH PAMAM dendrimer with metal salts (i.e., $\mathrm{K}_{2} \mathrm{PtCl}_{4}, \mathrm{CuCl}_{2}$ ) in water at room temperature for 1-2 weeks prior to reduction with $\mathrm{H}_{2}$ in solution. The atomic ratio of $\mathrm{Pt}-\mathrm{Cu}$ in the dendrimer varied from pure $\mathrm{Pt}$ to pure $\mathrm{Cu}$, with $\mathrm{Pt}_{30} \mathrm{Cu}_{10}, \mathrm{Pt}_{20} \mathrm{Cu}_{10}$, and $\mathrm{Pt}_{30} \mathrm{Cu}_{10}$ in between. TEM study was carried out using a Hitachi HF2000 FE TEM. Specimens were prepared by applying a few drops of diluted catalyst suspensions to holey carbon-coated beryllium grids.

Representative TEM images and particle size distributions of $\mathrm{Pt}_{30} \mathrm{Cu}_{10}$ and $\mathrm{Pt}_{20} \mathrm{Cu}_{20}$ bimetallic nanoparticles are shown in Figure 1. The particles are nearly spherical and the size is uniform. Analysis of over 200 randomly selected particles reveals that $\mathrm{Pt}-\mathrm{Cu}$ bimetallic nanoparticles have an average diameter of about $1.7 \mathrm{~nm}$, regardless the metal composition, which is very close to the calculated particle size in terms of a "fixed loading law" for the dendrimer (i.e., the size expected for 40 atoms per dendrimer). For example, the calculated particle size for $\mathrm{Pt}_{30} \mathrm{Cu}_{10}$ is $1.1 \mathrm{~nm}$ based on spherical shape, and $1.4 \mathrm{~nm}$ based on hemispherical shape, while for $\mathrm{Pt}_{20} \mathrm{Cu}_{20}$, it is $1.1 \mathrm{~nm}$ for sphere and $1.3 \mathrm{~nm}$ for hemisphere. In addition, energy dispersive spectroscopy (EDS) of these particles suggests that they are bimetallic in nature. Additional liquid-phase FTIR spectroscopic results collected during CO adsorption on these nanoparticles shows that a prominent peak appears at $2174 \mathrm{~cm}^{-1}$ for both samples. This peak is associated with terminally absorbed $\mathrm{CO}$ on $\mathrm{Cu}$, and the absence of a lower frequency (ca 2050-2080 $\mathrm{cm}^{-1}$ ) band for Pt suggests that a $\mathrm{Pt}_{\text {core }} \mathrm{Cu}_{\text {shell }}$ structure may be present [3]. The formation of quite mono-dispersed nanoparticles suggests the effectiveness of G4-OH dendrimer acting as both a template for the preparation of bimetallic $\mathrm{Pt}-\mathrm{Cu}$ nanoparticles, and a stabilizer to prevent the aggregation. Data will also be presented for supported $\mathrm{Pt}-\mathrm{Cu}$ catalysts synthesized using these nanoparticles as a precursor. 
In summary, dendrimer-stabilized nanoparticles appear to be promising methods for bimetallic catalyst synthesis. We have successfully been able to control the particle size distribution and dispersion of Pt-Cu nanoparticles [4].

[1] Rodriguez, J.A.; Goodman, D.W. J. Phys. Chem. (1991),95(11), 4196-206

[2] Tomalia, D.; Naylor, A.; Doddard, W. Angew. Chem . Int. Ed. Engl. (1990), 29, 138-175

[3] Miessner, H.; Landmesser, H.; Jaeger, N.; Richter, K. J. Chem. Soc., Faraday Transactions (1997), 93(18), 3417-3422.

[4] TEM study at the Oak Ridge National Laboratory (ORNL) High Temperature Materials Laboratory (HTML) was sponsored by the Assistant Secretary for Energy-Efficiency and Renewable Energy, Office of FreedomCAR and Vehicle Technologies, U.S. Department of Energy under contract DE-AC05-00OR22725 with UT-Battelle, LLC.
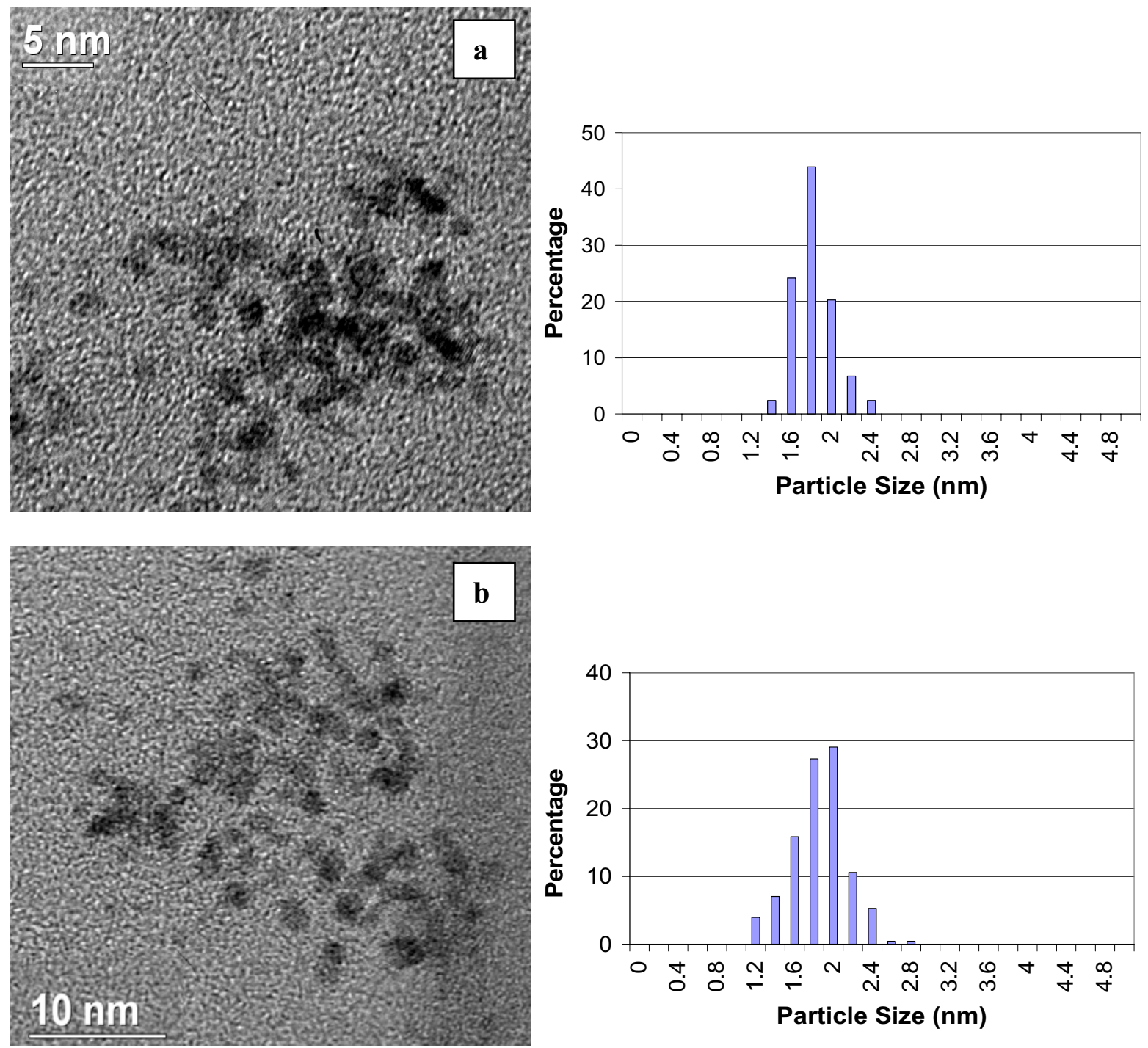

Figure 1. TEM images and particle size distribution of (a) $\mathrm{Pt}_{30} \mathrm{Cu}_{10}$ based on 207 randomly selected particles and (b) $\mathrm{Pt}_{20} \mathrm{Cu}_{20}$ based on 227 randomly selected particles. 